www.jmscr.igmpublication.org

Index Copernicus Value: 79.54

ISSN (e)-2347-176x ISSN (p) 2455-0450

crossref DOI: https://dx.doi.org/10.18535/jmscr/v7i5.11

Journal Of Medical Science And Clinical Research

IGM Publication

An Official Publication of IGM Publication

\title{
W Angle: Sagittal Jaw Dysplasia Indicator for orthodontic diagnosis
} outcome

Authors

\section{Dr Jamadgni Gor ${ }^{1}$, Dr Ajay Kubavat ${ }^{2}$, Dr Manish Desai ${ }^{3}$, Dr Khyati Mahida ${ }^{4}$, Dr Apexa Modh ${ }^{1}$, Dr Alpesh Vaghela ${ }^{1}$}

${ }^{1}$ Post graduate student, Department of Orthodontics and Dentofacial Orthopaedics, Narsinhbhai Patel Dental

College \& Hospital, Sankalchand Patel University, Visnagar, Gujarat, India

${ }^{2}$ Head of the Department, Department of Orthodontics and Dentofacial Orthopaedics, Narsinhbhai Patel

Dental College \& Hospital, Sankalchand Patel University, Visnagar, Gujarat, India

${ }^{3}$ Reader, Department of Orthodontics and Dentofacial Orthopaedics, Narsinhbhai Patel Dental College \&

Hospital, Sankalch and Patel University, Visnagar, Gujarat, India

${ }^{4}$ Senior lecturer, Department of Orthodontics and Dentofacial Orthopaedics, Narsinhbhai Patel Dental

College \& Hospital, Sankalchand Patel University, Visnagar, Gujarat, India

\section{Abstract}

Introduction and objective of study: This study was aimed to check the predictability, variability and also discuss the correlation between ANB angle, Wits appraisal and "W" angle with anterior and posterior sagittal discrepancy parameter.

Methodology: 40 lateral cephalograms were obtained which contains 15 Class-1 Malocclusion, 15 Class2 and 10 Class-3 patients with Age group of 10-25 years. The cephelograms were traced with the three different parameters (ANB angle, wits appraisal and $W$ angle). The $W$ angle is measured between the perpendicular from point $M$ on $S-G$ line andM-G.

Results: An analysis of variance was done between the groups to test for statistical significance. Categorical variables were evaluated with Pearson correlation test with level of significance P<0.05. Results showed that a patient with a W angle between 51 and 56 degrees can be considered to have a Class I skeletal pattern. With an angle less than 51 degrees, considered to have a skeletal Class II relationship and with an angle greater than 56 degrees, patients have a skeletal Class III relationship. Analysis was performed and highly significant differences were found in ANB, Wits Appraisal and W-angle in all the three Groups (Group I, Group II, and Group III).

Conclusion: It has been concluded that similar to the ANB and Wits Appraisal, the W-angle are also significant angles to assess the sagittal jaw relationship between maxilla and mandible. $W$ angle is more reliable and accurate.

Keywords: W angle, ANB ANGLE, wits appraisal, sagittal discrepancy.

\section{Introduction}

The evaluation of sagittal jaw relationship between maxilla and mandible has been one of the major problem in the field of orthodontics, which is of prime importance in diagnosis and treatment planning .This is because of rotations of jaws during growth, vertical relationships between the jaws and reference planes, and a lack of validity of the various methods proposed for their evaluation. 
Downs in 1948 introduced the A-B plane angle. Positive and negative signs were used to denote protrusion and retrusion of mandible. A few years later Riedel in1952 introduced ANB angle and It became the most commonly used.

However, both Down's and Riedel's methods are subject to error due to the variations in the position of nasion which is not fixed during the growth, and any displacement will be directly affecting the A-B plane angle and ANB angle.

As an alternative to ANB Jacobson introduced Wits appraisal in 1975. It relates points A and B to the functional occlusalplane. The distance between the points of intersection $\mathrm{AO}$ and $\mathrm{BO}$ is measured to describe antero-posterior relationship. In females, $\mathrm{AO}$ should coincide $\mathrm{BO}$, whereas in males BO should be 1 mmahead of AO. Though Wits appraisal avoids point N, accurate identification of functional occlusal plane is not easy or accurately reproducible, especially in mixed dentition patients. Secondly, any change in the angulation of functional occlusal plane, which is caused by either tooth eruption or dental development orthodontic intervention, can profoundly influence Wits appraisal.

Baik and Ververidou in 2004 introduced the beta angle. Though, it assesses sagittal discrepancies, it depends on points $\mathrm{A}$ and $\mathrm{B}$, which are difficult to locate and point $C$ in condyle which is not clearly visible either to overcome these problems Bhad et al (2011) developed W-angle. It does not depend on any unstable landmarks or dental occlusion and would be especially valuable to assess true sagittal changes because of growth and orthodontic treatment. So the purpose of this study is to compare the various angles ANB angle, Comparison of different angular measurements to assess sagittal Jaw discrepancy inWits appraisal, and W-angle used to measure anteroposteriordiscrepancy and to find out which is the most reliable amongst them.

\section{The $W$ angle}

The $\mathrm{W}$ angle is a new measurement for assessing the skeletal discrepancy between the maxilla and the mandible in the sagittal plane (Figure 1).
It uses three skeletal landmarks-point $S$, point $\mathrm{M}$, and point $\mathrm{G}$ - to measure an angle that indicates the severity and the type of skeletal dysplasia in the sagittal dimension (Figure 1).

The $\mathrm{W}$ angle can be found by, first, the following locating three points:

Point $\mathrm{S}$ - is the midpoint of the sella turcica;

Point $\mathrm{M}$ - is the midpoint of the premaxilla;

Point $\mathrm{G}$ - is the centre of the largest circle that is tangent to the internal inferior, anterior, and posterior surfaces of the mandibular symphysis.

Next, defining four lines:

Line connecting $\mathrm{S}$ and $\mathrm{M}$ points.

Line connecting $\mathrm{M}$ and $\mathrm{G}$ points

Line connecting $S$ and $G$ points.

Line from point $M$ perpendicular to the $S-G$ line.

Finally, measuring the $\mathrm{W}$ angle, which is the angle between the perpendicular line from point $\mathrm{M}$ to $\mathrm{S}$ $\mathrm{G}$ line and the $\mathrm{M}-\mathrm{G}$ line (Figure 1). The purposes of this study were to define the mean value and the standard deviation for this angle in people with the Classes I, II, and III skeletal pattern.

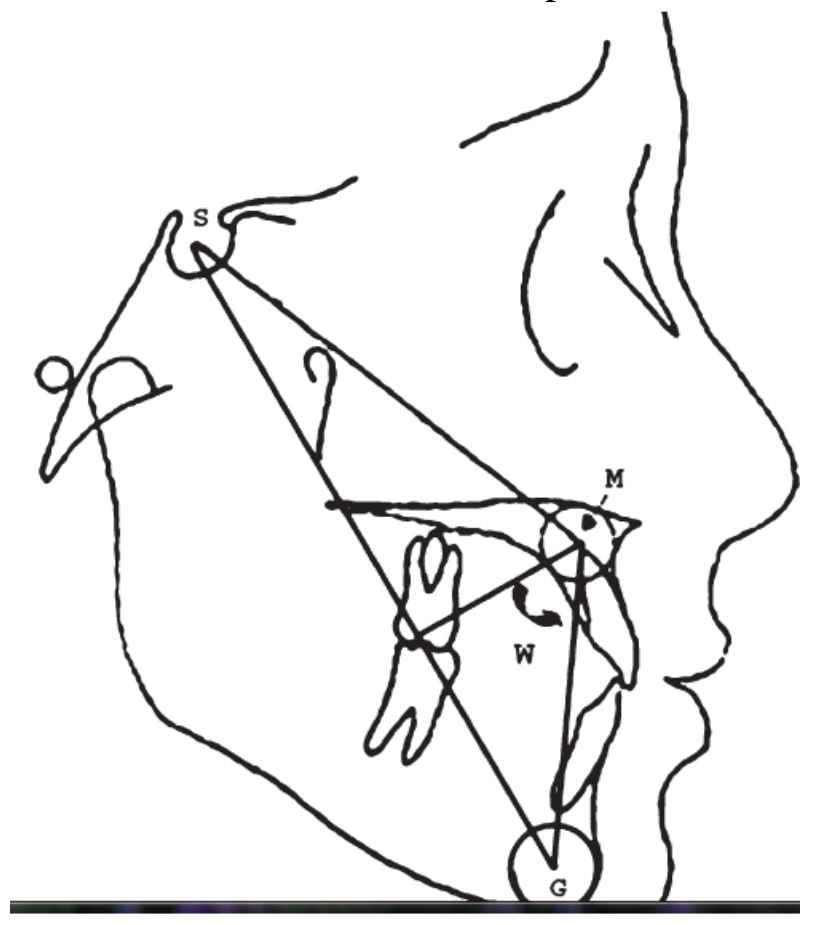

Figure-1 The construction and mode of measuring the $\mathrm{W}$ angle. 


\section{Material and Methods}

To assign samples 15 class-1malocclusion, 15 class-2 and 10 class-3 patient with Age group of 10-25 years were screened in the Department of Orthodontics and Dentofacial Orthopaedics NPDCH, SPU, Visnagar, Gujarat.

After the initial selection, all $\mathrm{x}$-rays were retraced; the ANB and the Wits appraisal were measured by each investigator separately. The mean values of those measurements were calculated. All tracings and measurements were repeated by the same operators at a 2 week interval. Combined error was calculated with Dahlberg's formula. The mean difference was within 0.7 degrees for angular measurements and was insignificant.

For a patient to be included in the Classes I, II, or III skeletal pattern group, Patient full filling the following criteria were included in the study:

\section{Class I}

1. ANB angle of $\geq 2^{\circ}$

2. Wits appraisal $\geq 2 \mathrm{~mm}$

\section{Class II}

1. ANB angle of $4^{\circ}$ to $8^{\circ}$

2. Wits appraisal angle was greater 4 to $8 \mathrm{~mm}$

\section{Class III}

1. ANB angle of 1 or less

2. Wits appraisal was greater than or equal -1 $\mathrm{mm}$

To construct the $\mathrm{W}$ angle, points $\mathrm{S}, \mathrm{M}$, and $\mathrm{G}$ were located. To locate points $\mathrm{M}$ and $\mathrm{G}$, as suggested by Nanda and Merrill (1994) and Braun et al. (2004), a template with concentric circles whose diameters increased in $1 \mathrm{~mm}$ increments was used.

\section{Angular measurements}

ANB angle: Difference between SNA and SNB

$\mathrm{W}$ angle: Angle between the perpendicular line from point $\mathrm{M}$ to $\mathrm{S}-\mathrm{G}$ line and the $\mathrm{M}-\mathrm{G}$ line

\section{Linear measurements}

Wits appraisal: Distance between $\mathrm{A}$ and $\mathrm{B}$ point on OP plane

After classifying the patients, W angle was measured by two operators and mean value was taken. To measure the method error using
Dahlberg's formula, same procedure was repeated after 2 weeks and it was found to be 0.5 degrees.

\section{Statistical Analysis}

Data was analysed using SPSS version 22. The tests performed are descriptive statistics and coefficient of variation to identify the most accurate parameters. Person Correlation test was used to know the Relation between various parameters in overall data and individual groups. The Mean and SD of the various parameters were obtained for each group. The correlation between $\mathrm{W}$ angle and various parameters compared. $\mathrm{P}$ value $<0.05$ is considered as statistically significant. Receiver operating characteristics curves were run to examine the sensitivity and specificity of $\mathrm{W}$ angle as a test to discriminate between three different skeletal pattern groups. All statistics were performed inSPSS version 22.

\section{Results}

Coefficient of variation was used to identify the most accurate parameter.

Pearson Correlation test was used to know the relation between various parameters in overall data and individual groups with level of significance $\mathrm{P}<0.05$.

According to the study, the mean value of w angle in

class I malocclusion is 53.67 where in

class II mean value is 46.20 . In

class III malocclusion mean of $\mathrm{w}$ angle is 62.80 . 
Table 1: Mean and SD of the various parameters in study groups

\begin{tabular}{|l|c|c|c|c|c|c|c|}
\hline Group & Parameter & $\mathrm{N}$ & Minimum & Maximum & Mean & Std. Deviation & $\begin{array}{c}\text { Coefficiant of } \\
\text { Variance }\end{array}$ \\
\hline Class I & ANB & 15 & 1.0 & 5.0 & 2.33 & 1.45 & 62.04 \\
\cline { 2 - 8 } & $\begin{array}{c}\text { WITS } \\
\text { APPRASIAL }\end{array}$ & 15 & 0.0 & 2.0 & 1.47 & 0.74 & 50.67 \\
\cline { 2 - 8 } & W angle & 15 & 50.0 & 56.0 & 53.67 & 2.23 & 4.15 \\
\hline Class II & ANB & 15 & 3.0 & 8.0 & 5.33 & 1.35 & 25.22 \\
\cline { 2 - 8 } & $\begin{array}{c}\text { WITS } \\
\text { APPRASIAL }\end{array}$ & 15 & 3.0 & 10.0 & 5.60 & 1.92 & 34.28 \\
\cline { 2 - 8 } & W angle & 15 & 42.0 & 55.0 & 46.20 & 3.19 & 6.90 \\
\hline Class III & ANB & 10 & -14.0 & 2.0 & -1.30 & 4.79 & -368.11 \\
\cline { 2 - 8 } & $\begin{array}{c}\text { WITS } \\
\text { APPRASIAL }\end{array}$ & 10 & -14.0 & -1.0 & -3.20 & 3.97 & -123.95 \\
\cline { 2 - 8 } & W angle & 10 & 55.0 & 76.0 & 62.80 & 5.43 & 8.65 \\
\hline \multirow{2}{*}{$\begin{array}{l}\text { Pooled } \\
\text { Data }\end{array}$} & ANB & 40 & -14.0 & 8.0 & 2.55 & 3.67 & 144.01 \\
\cline { 2 - 8 } & $\begin{array}{c}\text { WITS } \\
\text { APPRASIAL }\end{array}$ & 40 & -14.0 & 10.0 & 1.85 & 4.14 & 223.89 \\
\cline { 2 - 8 } & W angle & 40 & 42.0 & 76.0 & 53.15 & 7.40 & 13.93 \\
\hline
\end{tabular}

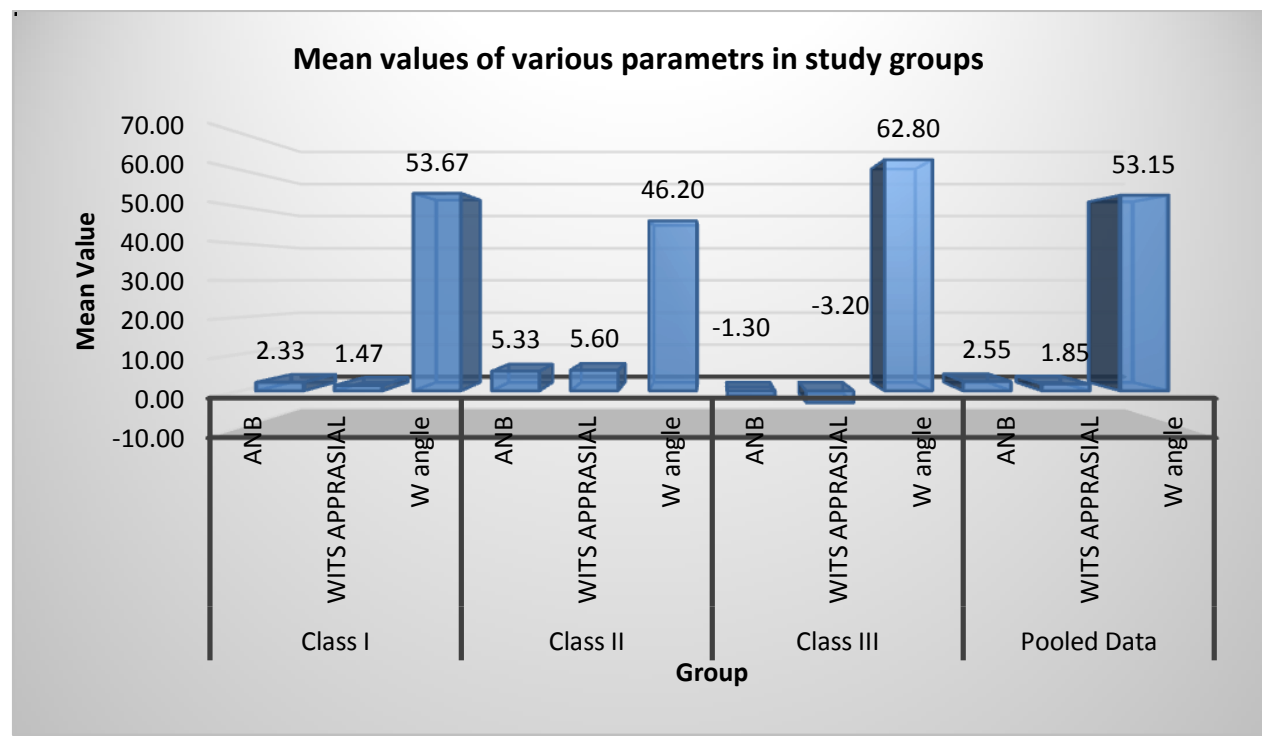

Table 2: Correlation between $\mathrm{W}$ angle and various parameters compared. (overall)

\begin{tabular}{|l|c|c|c|}
\hline Parameter & & ANB & WITS APPRASIAL \\
\hline \multirow{3}{*}{ W angle } & Pearson Correlation (r-value) & $-.852^{* *}$ & $-.918^{* *}$ \\
\cline { 2 - 4 } & P value & $<0.001$ & $<0.001$ \\
\cline { 2 - 4 } & $\mathrm{N}$ & 40 & 40 \\
\hline \multirow{2}{|l|}{$* *$. Correlation is significant at the 0.01 level (2-tailed). }
\end{tabular}

\begin{tabular}{|c|c|c|c|c|}
\hline Group & Parameter & & $\overline{\text { ANB }}$ & $\begin{array}{c}\text { WITS } \\
\text { APPRASIAL }\end{array}$ \\
\hline \multirow[t]{2}{*}{ Class I } & \multirow[t]{2}{*}{$\mathrm{W}$ angle } & Pearson Correlation (r-value) & -.407 & .014 \\
\hline & & $P$ value & .133 & .959 \\
\hline \multirow[t]{2}{*}{ Class II } & \multirow[t]{2}{*}{$\mathrm{W}$ angle } & Pearson Correlation (r-value) & -.450 & -.488 \\
\hline & & $P$ value & .093 & .065 \\
\hline \multirow[t]{2}{*}{ Class III } & \multirow[t]{2}{*}{$\mathrm{W}$ angle } & Pearson Correlation (r-value) & $-.832 * *$ & $-.904 * *$ \\
\hline & & $\mathrm{P}$ value & .003 & .000 \\
\hline
\end{tabular}

From the above table the following inferences can be drawn.

W angle is statistically significantly correlated with various parameters in group 3 but not in group $1 \&$ group 2. 


\section{Discussion}

In orthodontic diagnosis and treatment planning evaluation of the AP jaw relationship is a mandatory step and this relationship is generally determined by cephalometric analysis. To evaluate this relationship, various angular and linear measurements have been suggested. But these can be erroneous as angular measurements are affected by changes in face height, jaw inclination, and total jaw prognathism; linear variables can be affected by the inclination of the reference line (Williams et al., 1985; Jacobson, 1988).

The most popular parameter for assessing the sagittal jaw relationship remains the ANB angle, but it is affected by various factors and can often be misleading. When using ANB angle, factors like patient's age, growth rotation of the jaws, vertical growth, as well as length of the anterior cranial base (AP position of $\mathrm{N}$ ) should be considered, which makes the interpretation of this angle much more complex (Jacobson, 1975).

To overcome these problems, the Wits appraisal was introduced (Jacobson, 1975). Although not affected by landmarks or jaw rotations, it still has the problem of correctly identifying the functional occlusal plane, which can sometimes be impossible, especially in mixed dentition. Furthermore, changes of the Wits measurement throughout orthodontic treatment might also reflect changes in the functional occlusal plane rather than pure sagittal changes of the jaws (Moore et al., 1989; Ishikawa et al., 2000).

A popular recent alternative Beta angle avoids use of functional plane and is not affected by jaw rotations (Baik and Ververidou, 2004). But it uses point $\mathrm{A}$ and point $\mathrm{B}$, which can be remodelled by orthodontic treatment and growth (Richardson, 1982; Frank, 1983; Rushton et al., 1991). Furthermore, as shown by various studies, the reproducibility of the location of condylion on mouth-closed lateral head films is limited (Adenwalla et al., 1988; Moore et al., 1989; Ghafari et al., 1998). Instead of condylion, centre of condyle could be used, but approximation of centre of condyle is difficult (Baik and Ververidou, 2004). This could give a nonsignificant error of approximately 1 degree.

All other AP parameters introduced over the years are affected by at least one of the factors, namely patient's age, jaw rotations, poor reproducibility of landmarks, growth changes in reference planes, and changes due to orthodontic treatment (Ishikawa et al., 2000).

To overcome some of the limitations of the previously discussed parameters, the $\mathrm{W}$ angle was developed. This measurement does not depend upon the unstable landmarks or functional occlusal plane. It uses three stable points-point $\mathrm{S}$, point $\mathrm{M}$, and point $\mathrm{G}$. The $\mathrm{W}$ angle is measured between a perpendicular line from point $\mathrm{M}$ to the $\mathrm{S}-\mathrm{G}$ line and $\mathrm{M}-\mathrm{G}$ line. Based on statistical analysis, a patient with a $\mathrm{W}$ angle between 51 and 56 degrees has a Class I skeletal pattern. Patient with a $\mathrm{W}$ angle less than 51 degrees has a skeletal Class II pattern and one with a $\mathrm{W}$ angle greater than 56 degrees has a skeletal Class III pattern. In females with class III skeletal pattern,

$\mathrm{W}$ angle has a mean value of 57.4 degrees, while in males, it is 60.4 degrees.

Cranial base length (position of point $\mathrm{N}$ ) can sometimes camouflage the true skeletal classes I, II, and III patterns. In this regard, W angle can be a valuable tool for planning orthopaedic or orthognathic procedures as this angle is independent of cranial base length. Another advantage of Wangle is that it can be used for evaluation of treatment progress because it reflects true changes of the sagittal relationship of the jaws, which might be due to growth or orthodontic or orthognathic intervention.

However, by precisely tracing the premaxilla and locating its centre is not always easy. To accurately use this angle the cephalometric x-rays must be of high quality. It is then much easier for the clinician to follow the contour of premaxilla and locate its centre. In Class II and Class III skeletal cases, similar to Beta angle, $\mathrm{W}$ angle cannot determine which jaw is prognathic or retrognathic. To clarify this, clinician should be 
aware of importance of other cephalometric measurements.

Cephalometrics is not an exact science. Cephalometric analyses based on the angular and linear measurements have the obvious limitations and so dependency on any one parameter for skeletal assessment is discouraged. The $\mathrm{W}$ angle adds a valuable tool for assessment of AP jaw relationship. Along with other parameters, it should enable better diagnosis and treatment planning for patients.

\section{Conclusion}

Similar to the ANB and Wits Appraisal, the Wangle are also significant angle to assess the sagittal jaw relationship between maxilla and mandible. So $\mathrm{W}$ angle can be used as a substitute of ANB angle.

\section{Reference}

1. Bhad WA, Nayak S, Doshi UH. A new approach of assessing sagittal dysplasia: the W angle. Eur J Orthod2011;5:73-8.

2. Jacobson A. The Wits appraisal of jaw disharmony. Am J Orthod1975;67:125138.

3. Ram S. Nanda, DDS, MS, PhD, and Robert M. Merrill, DDS, MS. Cephalometric assesement of sagittal relationship between maxilla,Am J Orthod 1994;105:328-44.

4. Wendell 1. Wylie, D.D.S., M.S. The Assessment of Anteroposterior Dysplasia vol.xvII.Ncs.3-4 july-october 1947.

5. Riedel AR. The relation of maxillary structure to cranium in malocclusion and normal occlusion. Angle Orthod 1952;22 (3):142-5.

6. BaikCY,Ververidou M. A New Approach of Assessing Sagittal Discrepancies: the Beta Angle. Am J Orthod 2004; 126(1):100-5.
7. Hiroyuki Ishikawa, DDS, PhD, Shinji Nakamura, DDS, PhD,Hiroshi Iwasaki, DDS, PhD, and Shinichi Kitazawa, DDS, Seven Parameters describing anteroposterior jaw relationships: Postpubertal prediction accuracy and interchangeability ,Am J Orthod Dentofacial Orthop 2000;117:714-20). 